\title{
Role of Routine Histopathology of Gallbladder Specimen from Gallstone Disease to Detect Unsuspected Carcinoma
}

\author{
MJ ISLAM ${ }^{\mathrm{a}}, \mathrm{S}^{\mathrm{S}} \mathrm{KKTER}^{\mathrm{b}}$, AR TALUKDER $^{\mathrm{c}}$, MS HAQUE $^{\mathrm{d}}$
}

Summary:

Introduction: Carcinoma of the gallbladder is a malignancy with very high mortality rate. Unfortunately, our common practice to discard gallbladder specimens after cholecystectomy in unsuspected malignancy. This results in missing some premalignant conditions and early carcinomas. This study was conducted to find out the incidence of unsuspected gallbladder carcinoma from cholecystectomy patients in routine histopathology of specimens and analyze their clinico-pathological features.

Methods: This was a two years cross sectional study included 542 patients with acute or chronic cholecystitis secondary to cholelithiasis operated by cholecystectomy. All cases of carcinoma gallbladder, on clinical grounds or confirmed by radiology were excluded. Gallbladders showing gross abnormalities suggestive of localized or infiltrative malignancy during surgery were also excluded. All gallbladder specimens were send for histopathology examination.

Results: Over a period of two years, five hundred and fortytwo patients with symptomatic gallstones were admitted for

Introduction:

Carcinoma gallbladder is one of the worst cancer for its morbidity and mortality. It is a frequent underlying pathology in patients undergoing surgical intervention for chronic cholecystitis with cholelithiasis. ${ }^{1}$ Long standing chronic inflammation by gallstones is considered an important etiological role in carcinogenesis. The incidence of carcinoma gallbladder associated with gallstones varies from 0.3 to 12 percent. Histopathological analysis is therefore mandatory for diagnosis of early carcinomas.

\footnotetext{
a. Dr. Md. Jahidul Islam, Assistant Professor of Surgery, Shaheed M. Monsur Ali Medical College, Sirajganj.

b. Dr. Shaheen Akter, Associate Professor of Pathology, North Bengal Medical College, Sirajganj.

c. Dr. Abdur Rabban Talukder, Associate Professor of Surgery, Shaheed M. Monsur Ali Medical College, Sirajganj.

d. Dr. Md Shariful Haque, Assistant Professor of Nephrology, Shaheed M. Monsur Ali Medical College, Sirajganj.

Address of Correspondence: Dr. Md. Jahidul Islam, Assistant Professor, Surgery, Shaheed M Monsur Ali Medical College, Sirajganj. Mobile: 01712053831, E mail: drjahidul@gmail.com Received: 7 April, 2018

Accepted: 3 May, 2019
}

cholecystectomy. The male to female ratio was 1:3. Most of the patients (26.49\%) were found in fourth decade of life. Majority of patients (93.54\%) presented with upper abdominal pain of varying duration. All the specimens were sent for histopathology. Four hundred sixty cases (84.87\%) showed chronic cholecystitis (including intestinal metaplasia and dysplasia). Seventy of the cases (12.92\%) showed evidence of acute cholecystitis (including empyema and mucocele). Twelve gallbladders (2.21\%) showed evidence of adenocarcinoma of varying differentiation along with cholelithiasis.

Conclusion: Incidental diagnosis of carcinoma gallbladder is not rare. We strongly recommend to submit all cholecystectomy specimens routinely to histopathology laboratory, as this is the only means by which subclinical malignancies can be detected at an early stage.

Key word: Gallstone, Unsuspected carcinoma, Routine histopathology.

(J Bangladesh Coll Phys Surg 2019; 37: 186-190) DOI: http://dx.doi.org/10.3329/jbcps.v37i4.43348

Good prognosis and prolong survival is anticipated in patients with gallbladder carcinoma discovered as an incidental finding in early stage disease. ${ }^{2}$ Bangladesh is a highly populated country with a major fraction of population of lower socioeconomic status having less access to proper health facilities, a reason why early stage malignancy may escape detection leading to poor survival.

Discarding gallbladder specimens without histopathological analysis may results in missing discrete pathologies like premalignant lesions such as porcelain gallbladder, dysplasia, carcinoma-in-situ and early carcinomas. Our common practice is to do histopathology of only those gallbladder specimens which shows gross abnormality. This practice is based on the assumption that gallbladder carcinoma is always associated with macroscopic abnormalities. At the same time, this selective approach is justified by claiming that it reduces patient's financial liabilities and pathologist's workload. This contradicts to the worldwide practice where gallbladder specimen is routinely sent for histological analysis for the sole purpose of identifying discrete carcinoma in early stage. Gallbladder carcinoma 
is usually not suspected clinically nor detected by preoperative imaging. Indeed, when diagnosed by imaging, gallbladder cancer is usually advanced stage. Grossly, gallbladder carcinoma may present as a diffusely growing (70\%) or polypoid (30\%) mass. When diffuse, the gross distinction from chronic cholecystitis may be difficult. The fact that some gallbladder carcinomas are not obvious on gross examination indicates the need for microscopic examination of every excised gallbladder. Sometimes unexpected metastatic tumor can be found in the liver after the removal of a gallbladder thought to have only lithiasis and inflammation on gross examination by the surgeon and therefore discarded. ${ }^{3}$

With this background, we carried out this study with the following objectives: i) To find out the incidence of unsuspected gall bladder carcinoma with their clinicopathological analysis in routine histopathology of cholecystectomy specimens. ii) to assess the feasibility of performing histopathology in every specimen of gallbladder. This would ensure picking of unsuspected carcinoma of gallbladder, which in turn will assist in decreasing mortality rate.

\section{Methods:}

This was a two years cross sectional study, conducted in the Department of Surgery, Shaheed M Monsur Ali Medical College and 250 bed General Hospital, Sirajganj from 1st July 2015 to 30th June 2017. Study population were patients with acute or chronic cholecystitis secondary to cholelithiasis admitted and operated in General Hospital Sirajganj, North Bengal Medical College hospital and other hospitals in Sirajganj during the mentioned period. Five hundred and forty-two patients of cholelithiasis which were selected conveniently. Written informed consent was taken from all the patients.

Patients with evidence of carcinoma gallbladder, on clinical grounds and confirmed on ultrasonography and/ or CT scan were excluded. Gallbladders showing gross abnormalities suggestive of localized or infiltrative malignancy during surgery were excluded. Detailed history and thorough clinical examination of the patients was done with special attention to the right hypochondrium for preoperative assessment of palpable mass. Systemic review was done to see any co-morbidity. Baseline and specific investigations especially ultrasonography of abdomen and liver function tests were done in all patients. Clinical presentations, investigations, preoperative diagnosis and intraoperative findings were recorded in data sheet. All gallbladder specimens, were sent for histopathology.
Gross findings and histological diagnosis were noted from histopathology report. A predesigned proforma was used to put down the information gathered.

\section{Results:}

Over a period of two years, five hundred and forty-two patients with symptomatic gallstones were admitted for cholecystectomy. There were 130 males and 412 females with a male to female ratio of 1:3. The age ranged from 20 to 75 years with the mean age of 34 years (Table I). Most of the patients were found in fourth decade of life (146/ 542 cases, $26.94 \%)$. Majority of patients $(93.54 \%)$ presented with upper abdominal pain of varying duration. Other symptoms are depicted in Table II.

Table-I

\begin{tabular}{lcc}
\multicolumn{3}{c}{ Age distribution of the patients } \\
Age of patients (years) & No. of patients & $\%$ \\
\hline$\leq 20$ & 08 & 1.47 \\
$21-30$ & 124 & 22.88 \\
$31-40$ & 146 & 26.94 \\
$41-50$ & 112 & 20.66 \\
$51-60$ & 108 & 19.93 \\
$61-70$ & 40 & 7.38 \\
$71-80$ & 04 & 0.74 \\
\hline Total & 542 & 100 \\
\hline
\end{tabular}

Table-II

Common presenting symptoms of the patients

\begin{tabular}{lcc} 
Symptoms & No. of patients & $\%$ \\
\hline Upper abdominal pain & 507 & 93.54 \\
Flatulence and/ or dyspepsia & 323 & 59.59 \\
Intolerance to fatty food & 70 & 12.91 \\
Nausea and/ or vomiting & 66 & 12.17 \\
\hline
\end{tabular}

All 542 gallbladders were palpated and were opened per-operatively for any focal or diffuse thickening of the gallbladder wall, a raised mucosal plaque, polypoid growth or an infiltrating mass. The specimens were then sent for histopathology. Seventy of the cases (12.92\%) showed evidence of acute cholecystitis (including empyema and mucocele). Four hundred sixty cases $(84.87 \%)$ showed chronic cholecystitis (including intestinal metaplasia \& dysplasia). Twelve gallbladders $(2.21 \%)$ showed evidence of adenocarcinoma of varying differentiation along with cholelithiasis, (Table III). 
Table-III

\begin{tabular}{lcccc}
\multicolumn{2}{c}{ Histopathological findings of the cases } & & & \\
Histopathology & Male & Female & Total & $\%$ \\
\hline Acute cholecystitis (including empyema, mucocele) & 32 & 38 & 70 & 12.92 \\
Chronic cholecystitis (including intestinal metaplasia \& dysplasia) & 96 & 364 & 460 & 84.87 \\
Adenocarcinoma & 2 & 10 & 12 & 2.21 \\
\hline Total & 130 & 412 & 542 & 100 \\
\hline
\end{tabular}

There were twelve incidental or non-suspected carcinomas with no gross abnormalities in this series. Subsequent staging revealed nine adenocarcinomas in stage $\mathrm{T} 1$ and three in stages $\mathrm{T} 2$, none with distant metastasis. Nine patients with $\mathrm{T} 1$ tumors did not undergo any further procedure; three patients with stage $\mathrm{T} 2$ referred to hepatobiliary surgeons for revision surgery.

\section{Discussion:}

Gall bladder carcinoma has a high mortality rate because of its late presentation, high propensity to metastasize and lack of effective therapy. In the United states, it continues to be a rare cancer and it is thought to be disease of elderly. ${ }^{4}$ The scenario is, however, different in this study. Most of the patients of this study were found in fourth decade of life.

In this study, male to female ratio is $1: 3$. Female predominance is also reported by similar study (Channa et al., 2007). ${ }^{5}$ The mean age 34 years ranging from 20 to 75 years. This is slightly earlier than that reported in other studies from India (Pandey et al., 2001; Kapoor et al., 2003). ${ }^{6,7}$ Increasing detection rate at early age may be due to increasing awareness, accessibility to health care facilities and also may due to geographical distribution.

Over ninety-three per cent patients presented with pain in upper abdomen, a number significantly lower than that reported by Laghari et al, where all patients had upper abdominal pain. ${ }^{8}$ That may be due to routine use of proton pump inhibitors in our practice. We exclude the patients had any evidence of malignancy either clinically or on ultrasound examination.

Chronic cholecystitis was the most common histopathological finding in this study. Specimen of 460 $(84.87 \%)$ patients were reported as chronic inflammation with mucosal ulceration, denudation, metaplasia to dysplasia and wall infiltration by chronic inflammatory cells. A similar study by Memon also reports chronic cholecystitis as major histopathological finding, identified in $64.8 \%$ cases. In this study, 70 (12.92\%) cases were reported as acute cholecystitis including empyema and mucocele of gallbladder. In contrast Memon reported $31.5 \%$ as acute cholecystitis. ${ }^{9}$

In this series, incidental carcinoma of gallbladder was found in 12 cases $(2.21 \%)$. These gallbladders showed no gross abnormality per-operatively. Whereas its incidence was less i.e. $0.3 \%$ and $1.1 \%$ in the series according to Daphna et $\mathrm{al}^{10}$ and Morere et al ${ }^{11}$ respectively. It was even higher, as shown by Shigeki et al, $4.7 \%$ of incidental gallbladder carcinoma. ${ }^{12}$ Wide range of variation in incidence in different studies, might be due to difference in total number of study population of cholecystectomy cases carried out for the study purpose. Incidence of primary gallbladder carcinoma itself is low and finding of incidental carcinoma would be low too.

In this study all patients presented with history of chronic cholecystitis or acute cholecystitis. We exclude patients with any clinical features or investigation findings on favor of carcinoma gallbladder. Gallbladder malignancy usually does not have any characteristic clinical features. Over 90 per cent of patients presenting with symptoms of acute or chronic cholecystitis. ${ }^{13}$ Ultrasound has a high diagnostic accuracy for both advanced and early gallbladder cancer. None of the twelve carcinomas in this series were picked on preoperative ultrasound. In addition, all these twelve gallbladder specimens showed no macroscopic evidence of malignancy when they were opened during surgery. This is in contrast to the study by De Zoyasa et al. in whom all four cancers were suspected either on preoperative ultrasound or grossly during surgery; they suggest a more selective approach to gallbladder histology which may have saved both time and cost 
without having any unfavorable effects on patients wellbeing. ${ }^{14}$ Similar observations and recommendations are made by other studies. ${ }^{15,16}$ The issue of routine histopathology of all gallbladder specimen therefore remains unresolved; the need to send every specimen for histopathology or otherwise therefore depends on the expertise of the ultrasonologist as it depends on the skill of the operating surgeon. There is widespread variation in the practice of general surgeons regarding intra operative examination as well as submission of specimens for histopathology, in developing countries. ${ }^{17} \mathrm{We}$, however, advocate routine histopathology of all gallbladders removed at surgery since the subsequent report would provide evidence of incidental malignancy on solid grounds.

Chronic inflammation, infection and gall stones - are currently believed to be the factors leading to malignant transformation of gall bladder epithelium. ${ }^{18}$ Carcinoma gallbladder has a strong association with gallstones. ${ }^{19}$ The strong association between the two warrants attention paid to histopathology of specimen in all cases undergoing cholecystectomy for cholelithiasis, irrespective of presence or otherwise of any gross abnormalities. It is widely reported that long standing mucosal irritation by the stones cause atypical cellular changes and increased cellular proliferation. It has been hypothesized that in long standing cases, these areas of hyperplasia progress to metaplasia and carcinomain- situ. Studies confirm presence of such changes in the vicinity of gallbladder carcinoma. ${ }^{20}$

In this study the incidental carcinomas (3/4) were at very early T1 stage ( 9 of 12 carcinomas) and not a single case was found with distant metastasis. Tantia et al and Vincenzo et al found the majority of incidental carcinomas at early stage. ${ }^{21,22}$ Most of the incidentally detected carcinomas are surgically resectable, with a good survival rate. ${ }^{23}$ This study revealed all of them in pathological T1 and T2 stage and none with distant metastasis. Though simple cholecystectomy is said to be sufficient in stages $\mathrm{T} 1$ carcinomas, radical reresection is strongly recommended in stages beyond that. Yi et al. (2013) suggested that the reoperation should be performed as soon as possible, preferably within 10 days after the initial operation. ${ }^{24}$ This reflects the importance of histopathological study of all cholecystectomy specimens, irrespective of clinical impression.
All twelve cases of incidentally detected carcinoma had associated gallstones, thereby strongly supporting the role of chronic irritation by long standing gallstones as etiological factor for carcinoma gall bladder. All the cases are adenocarcinoma, no case of squamous cell carcinoma, or other variant of cancerous histopathology seen.

\section{Conclusion:}

Incidental diagnosis of carcinoma gallbladder is not rare. We showed evidence of malignancy in twelve $(2.21 \%)$ cases on subsequent histopathological examination of gallbladder specimen, which had no gross features of cancer. These cases had neither symptom suggestive of underlying malignancy nor was cancer reported on any of the preoperative investigations. We therefore recommend, each and every cholecystectomy specimen should be routinely submitted to histopathology laboratory, as gall bladder cancer can be detected at an early, potentially curable stage and unsuspected carcinoma can be detect only by histopathological examination.

\section{Acknowledgement:}

We would like to thank all the staffs of pathology department, North Bengal Medical College, Sirajganj, for their support during this study. The study was selffunded.

\section{References:}

1. Siddique K, Ali Q, Mirza S, Jamil A, Ehsan A, Latif S, Malik AZ. Evaluation of the aetiological spectrum of obstructive jaundice. J Ayub Med Coll Abbottabad 2008; 20(4): 62-66.

2. Inui K, Yoshino J, Miyoshi H. Diagnosis of gallbladder tumors. Intern Med 2011; 50(11): 1133-36.

3. Chan J K, Arber D A, Brunning R D, Desmet V J, Demasters BK K, Ordonez N G, Rosenblum M K, Tallini G. Gallbladder and extrahepatic bile ducts. In: Juan Rosai. Rosai and Ackerman's Surgical Pathology. Tenth Edition. Elsevier, New York. 2011. 1044-49.

4. Dipti K, Leela P, Sompal S, Gaurav J, Madhur K, Kusum G, Charanjeet $\mathrm{K}$. Impact of routine histopathological examination of gallbladder specimens on early detection of malignancy- a study of 4,115 cholecystectomy specimens. Asian Pac J Cancer Prev 2013;14: 3315-18.

5. Channa NA, Soomro AM, Ghangro AB. Cholecystectomy is becoming an increasingly common operation in Hyderabad and adjoining areas. Rawal Med J 2007; 32(2):128-30.

6. Pandey M, Pathak AK, Gautam A, Aryya NC, Shukla VK. Carcinoma of the gallbladder: a retrospective review of 99 cases. Digest Dis and Sci 2001; 46: 1145-51. 
7. Kapoor VK, Mc Michael AJ. Gallbladder cancer: an 'Indian' disease. Natl Med J Ind 2003; 16: 209-13.

8. Laghari AA, Talpur KAH, Malik AM, Khan SA, Memon AI. Laparoscopic Cholecystectomy in complicated gallstone disease. J Liaquat Uni Med Health Sci 2008; $7(1): 18-24$.

9. Memon W, Khanzada TW, Samad A, Kumar B. Histopathology spectrum of gallbladder specimens after cholecystectomy. Pak J Med Sci 2011; 27(3): 533-36.

10. Dephna W, Mehrdad H, Noa BJ, Sandbanand AH. Incidental finding of gallbladder carcinoma. Israel Med Assoc J 2002; 4: 334-36.

11. Morera Ocon FJ, Bullestin Vicente J, Ripoll Orts F, Landete Molina F, Garcia granero Ximenez M, Millan Tarin J, Tursi Rispoldi Ld, Bernal Sprekelsen JC. Gallbladdre cancer in a regional hospital. Cir Esp 2009; 86: 219-23.

12. Shigeki Y, Yasuo A, Yoshiaki M, Tetsuya S, Yutaka K, Tomohiro K, Masao A, Takashi T. Occult Gallbladder carcinoma after laparoscopic cholecystectomy: A report of four cases. J Nippon Med Sch 2007;74: 300-5

13. Moin M. Mode of presentation of carcinoma of gallbladder. Ann King Edward Med Coll 2000; 10(10): 234-35.

14. De Zoysa MI, De Silva SK III. Is routine histopathological examination of gallbladder specimens justifiable? Ceylon Med J 2010; 55(1):13-16.

15. Bazoua G, Hamza N, Lazim T. Do we need histology for a normal-looking gallbladder? J Hepatobiliary Pancreat Surg 2007; 14(6): 564-68.

16. Darmas B, Mahmud S, Abbas A, Baker AL: Is there any justification for the routine histological examination of straightforward cholecystectomy specimens? Ann R Coll Surg Engl 2007; 89(3):238-41.
17. Samad A, Kumar B, Khanzada TW. Practice of surgeons regarding examination of pathological specimens in operating room. J Ayub Med Coll Abbottabad 2009; 21: 137-42.

18. Hamdani NH, Qadri SK, Aggarwalla R, Bhartia VK, Chaudhuri S, Debakshi S, Baig SJ, Pal NK. Clinicopathological Study of Gall Bladder Carcinoma with Special Reference to Gallstones: Our 8-year Experience from Eastern India. Asian Pac J Cancer Prev 2012; 13(11): 5613-17.

19. Ayyaz M, Waris M, Fahim F. Presentation and etiological factors of cancer gall bladder in patients undergoing cholecystectomies at Mayo Hospital, Lahore. Ann King Edward Med Coll 2001; 7:138-40.

20. Sarma NH, Ramesh K, Gahukamble LD, Fituri OM, Mangal DK. Gall bladder cancer in north eastern Libya. East Afr Med J 1998; 75(7):417-21.

21. Tantia O, Jin M, Khanna S, Sen B. Incidental carcinoma gallbladder during laparoscopic cholecystectomy for symptomatic gallstone disease. Surg Endosc 2008; 23(9): 2041-46.

22. Vincenzo C, Enrico F, Cristina P, Alessandro DC, Roberto C, Gaspare G, Patrizia V. Early gallbladder carcinoma: A single-center experience. Tumori 2006; 92: 487-90.

23. Mazer LM, Losada HF, Chaudhry RM, Ramirez GAV, Donohue JH, Kooby DA, Nagorney DM, Adsay NV, Sarmiento JM. Tumor characteristics and survival analysis of incidental versus suspected gallbladder carcinoma. J Gastrointest Surg 2012; 16(7): 1311-17.

24. Yi X, Long X, Zai H, Xiao D, Li W, Li Y. Unsuspected gallbladder carcinoma discovered during or after cholecystectomy: focus on appropriate radical re-resection according to the T-stage. Clin Transl Oncol 2013; 15: $652-58$. 